\title{
Fostering an Environment for Research: A Fellow's Perspective
}

\author{
Harry C. Karydes
}

Published online: 26 April 2011

(C) American College of Medical Toxicology 2011

As I am completing my toxicology fellowship, I reflect on the many wonderful experiences I have had-from daily case discussions to giving lectures to students and physicians. However, as I continue in academic medicine, I am reminded of the additional expectations that await me, especially in the area of research. The axiom of "publish or perish" has been a constant reminder of the importance of publication of scholarly research to not only further my own knowledge but to advance my career in academia. As I started fellowship training, the prospect of "doing research" was foreign and alien to me. After appreciating the support of mentors and senior faculty, the notion of research and writing in academic journals seemed less mysterious and proved to be an exciting and enriching experience.

As with many elements in education, a strong foundation is paramount. I recognized that my initial aversion to research was simply a result of not having the necessary fundamental knowledge of basic research. Early in my academic career, I participated in the Emergency Medicine Basic Research Skills (EMBRS) workshop coordinated by experienced investigators at the headquarters of the American College of Emergency Physicians. This is an intense 11-day, two-session workshop that provides a basic overview on research concepts and suggestions for developing important fundamental guidelines for publication [1]. The EMBRS workshop also highlights critical research components from working with the Institutional Review Board to writing grant proposals. This course has really demystified the research process and settled some of my initial concerns related to academic writing.

H. C. Karydes $(\bowtie)$

Cook County Hospital (Stroger),

Chicago, IL, USA

e-mail: hkarydes@ccbh.org
Armed with the skills learned from EMBRS, I was ready to begin a double-blinded, multi-center study. However, as I look on my desk and dry-erase board of all of my "good ideas", I have been hampered by the action of simply putting these to paper. Fortunately (or perhaps unfortunately), my seemingly private struggle is actually quite common. There are studies that demonstrate that up to one third of abstracts presented at biomedical meeting are never published as complete articles in peer-reviewed journals [2-4]. One study found that some reasons for failure to publish ranged from lack of time to prepare a manuscript (most common reason cited) to lack of participation from co-authors to feelings that the responsibility of writing the manuscript belonged to another co-author [3].

While I admit that I have fallen victim to many of the reasons highlighted, my program has a number of solutions to assist fellows in the development of research. First, dedicated monthly research meetings provide an excellent forum to help move our projects forward. With the assistance of co-fellows and senior faculty members, this relaxed, nonjudgmental environment has provided me an opportunity to develop ideas, create realistic goals, and revise current manuscripts. These brainstorming sessions have helped me realize that while randomized-controlled research trials are valued in academia, there is a role for other types of publications such as case reports $[5,6]$ and book reviews. Second, I have been encouraged to create a "time to write". Following the advice of a recent article written in Academic Emergency Medicine, Dr. Lowenstein encourages individuals to "protect a few extra hours each week-hours that can be used for writing, study, selfrenewal, or the "quiet pursuit of knowledge" [7]. This last activity has been the most important for me. Although I have been given all the necessary provisions, the onus ultimately belongs to me. 
When I began my fellowship training, the prospect of setting up and initiating research projects seemed daunting especially with various other necessary responsibilities of fellowship. In retrospect, I now realize that those feeling were unnecessary. Having been given many wonderful opportunities to support my growth as a fellow and junior investigator, I look forward to using the tools I have gained during my training toward cultivating a successful career in academia.

\section{References}

1. http://www.acep.org/content.aspx?id=22386. Accessed 10 Feb 2011
2. Smollin CG, Nelson LS (2006) Publication of abstracts presented at 2001 NACCT. J Med Toxicol 2:97-100

3. Sprague S, Bhandari M, Devereaux PJ, Swiontkowski MF, Tornetta P 3rd, Cook DJ, Dirschl D, Schemitsch EH, Guyatt GH (2003) Barriers to full-text publication following presentation of abstracts at annual orthopaedic meetings. J Bone Joint Surg Am 85-A:158-163

4. von Elm E, Costanza MC, Walder B, Tramèr MR (2003) More insight into the fate of biomedical meeting abstracts: a systematic review. BMC Med Res Methodol 3:12

5. Tomasziewski C (2006) The power of the case report. J Med Toxicol 2:139-140

6. Ruha AM (2009) The case report: a tool for the toxicologist. J Med Toxicol 5:1-2

7. Lowenstein SR (2009) Tuesdays to write...a guide to time management in academic emergency medicine. Acad Emerg Med $16: 165-167$ 